\title{
EKSISTENSI GUBERNUR SEBAGAI WAKIL PEMERINTAH PUSAT DI DAERAH
}

\author{
Oleh: \\ Rahyunir Rauf \\ Program Pasca Sarjana Ilmu Pemerintahan \\ Universitas Islam Riau \\ Correspondence Author: rahyunir.ip@soc.uir.ac.id
}

\begin{abstract}
Abstrak
Dalam sistem pemerintahan Nasional Indonesia diakui keberadaan dari pemerintahan daerah, daerah terdiri dari daerah Provinsi, daerah Kabupaten dan daerah Kota. Daerah Provinsi dikepalai oleh seorang Gubernur, daerah Kabupaten dikepalai oleh seorang Bupati dan daerah Kota dikepalai oleh seorang Walikota. Berdasarkan Undang-Undang Nomor 23 Tahun 2014 tentang Pemerintahan Daerah menempatkan Gubernur pada 2 (dua) fungsi, yakni; Sebagai Kepala daerah dan Sebagai Wakil Pemerintah Pusat di Daerah. Gubernur sebagai wakil pemerintah pusat di daerah mendapatkan pelimpahan kewenangan dari pemerintah untuk melaksanakan urusan pemerintahan pusat di daerah. Sebagai wakil pemerintah pusat di daerah gubernur melaksanakan urusan absolut dan melaksanakan sub urusan pemerintah konkuren yang menjadi kewenangan pemerintah pusat serta melaksanakan pembinaan dan pengawasan terhadap daerahkabupaten/kota dalam melaksanakan urusan konkuren yang menjadi kewenangan pemerintah daerah kabupaten/kota. Dalam penyelenggaraan urusan pemerintah pusat di daerah diperlukan adanya wakil pemerintah pusat di daerah dan instansi vertikal. Sebelum dikeluarkannya Undang-Undang Nomor 23 Tahun 2014 terkait dengan Gubernur sebagai wakil pemerintah pusat di daerah diatur pada Undang- Undang Nomor 32 Tahun 2004 tentang pemerintahan daerah dan ditindaklanjuti dengan Peraturan Pemerintah Republik Indonesia Nomor 7 Tahun 2008 tentang Dekonsentrasi dan Tugas pembantuan. Dalam Undang-Undang Nomor 23 tahun 2014 tentang Pemerintahan Daerah dinyatakan bahwa wakil pemerintah pusat di daerah hanya diberikan kepada Gubernur, sedangkan Bupati/Walikota tidak mendapatkan kewenangan sebagai wakil pemerintah pusat di daerah. Dalam melaksanakan pembinaan dan pengawasan terhadap penyelenggaraan urusan pemerintahan yang menjadi kewenangan daerah kabupaten/kota dan tugas pembantuan oleh daerah kabupaten/kota, Presiden dibantu oleh Guberur sebagai wakil pemerintah pusat.
\end{abstract}

Kata Kunci; Pemerintah Pusat, Pemerintahan Daerah, Gubernur, Wakil pemerintah pusat di daerah. 


\begin{abstract}
In the Indonesian national government system is recognized the existence of local government, the region consists of provincial, district and municipal areas. The Provincial Region is headed by a Governor, a Regency area headed by a Regent and a City area headed by a Mayor. Based on Law Number 23 Year 2014 on Regional Government placed the Governor in 2 (two) functions, namely; As Headof Region and As Deputy of Central Government in Region. The governor as the representative of the central government in the regions gained the delegation of authority from the government to carry out central government affairs in the regions. As a representative of the central government in the region the governor carries out the absolute affairs and implements the concurrent governmental affairs which are the authority of the central government and conducts the guidance and supervision of the districts / municipalities in carrying out theconcurrent affairs which are the authority of the district / city government. In the implementation of central government affairs in the region it is necessary to have central government representatives in the regions and vertical institutions. Prior to the issuance of Law Number 23 Year 2014 in relation to the Governor as the representative of the central government in the regions is regulated in Law Number 32 Year 2004 regarding regional government and followed up by Government Regulation No. 7 of 2008 on Deconcentration and Co- Administration. In Act No. 23 of 2014 on Regional Government it is stated that the representative of central government in the regions is only given to the Governor, while the Regent / Mayor does not get the authority as a representative of the central government in the region. In carrying out the guidance and supervision on the implementation of government affairs which is the authority of the district / city and the task of assistance by the district / city, the President is assisted by the Governor as the representative of the central government.
\end{abstract}

Keywords; Central Government, Local Governments, Governors, Central government representatives in the regions.

\section{Latar Belakang}

Dalam sistem pemerintahan Nasional Indonesia diakuikeberadaan dari pemerintahan daerah, daerah terdiri dari daerah Provinsi, daerah Kabupaten dandaerah Kota. Daerah Provinsi dikepalai oleh seorang Gubernur, daerah Kabupaten dikepalai oleh seorang Bupati dan daerah kota dikepalai oleh seorang Walikota. Berdasarkan UndangUndang Nomor 23 Tahun 2014 tentang Pemerintahan
Daerah menempatkan Gubernur pada 2 (dua) fungsi, yakni;

1. Sebagai Kepala daerah

2. Sebagai Wakil Pemerintah Pusat di Daerah

Sebagai kepala daerah Gubernur merupakan unsur penyelenggara pemerintahan daerah bersama-sama dengan Dewan Perwakilan Rakyat Daerah (DPRD) dan dibantu oleh perangkat daerah yang berdasarkan kepada asas 
otonomi daerah atau asas desentralisasi.

Sedangkan sebagai wakil pemerintah pusat di daerah Gubernur merupakan perpanjangan tangan Presiden di daerah berdasarkan asas dekonsentrasi. Asas dekonsentrasi berdasarkan UU Nomor 23 Tahun 2014 adalah; "Pelimpahan kewenangan dari pemerintah kepada Gubernur sebagai wakil pemerintah pusat dan kepada instansi vertikal untuk menyelenggarakan urusan pemerintah pusat di daerah".

Berdasarkan Pasal di atas,dapat diketahui bahwa Gubernur sebagai wakil pemerintah pusat mendapatkan pelimpahan

kewenangan dari pemerintah untuk melaksanakan urusan pemerintahan pusat di daerah. Sebagai wakil pemerintah pusat di daerah Gubernur melaksanakan urusan absolut dan melaksanakan sub urusan pemerintah konkuren yang menjadi kewenangan pemerintah pusat serta melaksanakan pembinaan dan pengawasan terhadap daerah kabupaten/kota dalam melaksanakan urusan konkuren yang menjadi kewenangan pemerintah daerah kabupaten/kota.

Pembahasan

Gubernur Sebagai Wakil

\section{Pemerintah Pusat di Daerah}

Dalam penyelenggaraan urusan pemerintah pusat di daerah diperlukan adanya wakil pemerintah pusat di daerah dan instansi vertikal. Sebelum dikeluarkannya UndangUndang Nomor 23 Tahun 2014 terkait dengan Gubernur sebagai wakil pusat di daerah diatur pada UndangUndang Nomor 32 tahun2004 tentang pemerintahan daerah dan ditindaklanjuti dengan Peraturan
Pemerintah Republik Indonesia Nomor 7 Tahun 2008 tentang Dekonsentrasi dan Tugas Pembantuan.

Dalam Undang-Undang Nomor 23 Tahun 2014 tentang Pemerintahan Daerah dinyatakan bahwa wakil pemerintah pusat di daerah hanya diberikan kepada Gubernur, sedangkan Bupati/Walikota tidak mendapatkan kewenangan sebagai wakil pemerintah pusat di daerah.

Berdasarkan Pasal 91 ayat (1) Undang-Undang Nomor 23 Tahun 2014 dinyatakan bahwa; "Dalam melaksanakan pembinaan dan pengawasan terhadap penyelenggaraan urusan pemerintahan yang menjadi kewenangan daerah Kabupaten/Kota dan tugas pembantuan oleh daerah Kabupaten/Kota, Presiden dibantu oleh Guberur sebagai wakil pemerintah pusat.

Dalam membantu melaksanakan urusan pemerintah yang menjadi kewenangan pemerintah pusat di daerah maka ditetapkan gubernur sebagai wakil pemerintah pusat, berdasarkan Pasal 91 ayat (2) UU Nomor 23 Tahun 2014, tugas Gubernur sebagai wakil pemerintah pusat di daerah adalah:

a. Mengkoordinasikan pembinaan dan pengawasan penyelenggaraan tugas pembantuan di daerah kabupaten/kota.

b. Melakukan monitoring, evaluasi dan supervisi terhadap penyelenggaraan pemerintahan daerah kabupaten/kota yang ada diwilayahnya.

c. Memberdayakan dan memfasilitasi daerah 
kabupaten/kota di wilayahnya.

d. Melakukan evaluasi terhadap rancangan Perda kabupaten/kota di wilayahnya tentang RPJPD, RPJMD, APBD, Perubahan APBD, Pertanggungjawaban pelaksanaan APBD, tata ruang daerah, pajak daerah dan retribusi daerah.

e. Melakukan pengawasan terhadap Perda Kabupaten/Kota

f. Melakukan tugas lain sesuai dengan ketentuan peraturan perundang-undangan.

Berdasarkan Pasal di atas dapat diketahui bahwa tugas Guberbur sebagai wakil pemerintah pusat di daerah dalam bentuk koordinasi, pengawasan dan pembinaan terhadap pemerintah daerah kabupatenkota yang ada di wilayah Provinsi yang bersangkutan.

Selain dari memiliki tugas, maka Gubernur sebagai wakil pemerintah pusat di daerah juga memiliki wewenang seperti dinyatakan pada Pasal 91 ayat (3) Undang-Undang Nomor 23 Tahun 2014, yakni;

a. Membatalkan Perda Kabupaten/Kota dan Peraturan Bupati/Walikota.

b. Memberikan penghargaan dan sanksi terhadap Bupati/Walikota terkait dengan penyelenggaraan pemerintahan daerah.

c. Menyelesaikan perselisihan dalam penyelenggaraan fungsi pemerintahan antardaerah kabupaten/kota dalam 1 (satu) provinsi. d. Memberikan persetujuan terhadap rancangan Perda kabupaten/kota tentang pembentukan dan susunan perangkat daerah kabupaten/kota.

e. Melaksanakan wewenanga lain sesuai dengan peraturan perundang-undangan.

Sehubungan dengan keberadaan wakil pemerintah pusatdi daerah terdapat adanya perbedaan dari Undang-Undang Nomor 32 Tahun 2004 tentang Pemerintahan Daerah dengan Undang-Undang Nomor 23 Tahun 2014 tentang Pemerintahan Daerah, untuk jelasnya dapat dilihat pada tabel berikut ini.

Tebel. 1 Perbandingan Wakil Pemerintah Pusat Di Daerah Antara UU Nomor 32 Tahun 2004 Dengan UU Nomor 23 Tahun 2014

\begin{tabular}{|c|c|c|c|}
\hline $\begin{array}{l}\mathbf{N} \\
\mathbf{0}\end{array}$ & $\begin{array}{c}\text { Indikator } \\
\text { Perbandi } \\
\text { ngan }\end{array}$ & $\begin{array}{c}\text { UU } \\
\text { Nomor } \\
32 \\
\text { Tahun } \\
2004 \\
\end{array}$ & $\begin{array}{c}\text { UU } \\
\text { Nomor } \\
23 \\
\text { Tahun } \\
2014 \\
\end{array}$ \\
\hline 1 & Gubernur & $\begin{array}{l}\text { Wakil } \\
\text { Pemeri } \\
\text { ntah } \\
\text { Pusat }\end{array}$ & $\begin{array}{l}\text { Wakil } \\
\text { Pemerint } \\
\text { ah Pusat }\end{array}$ \\
\hline 2. & $\begin{array}{l}\text { Wakil } \\
\text { Gubernur }\end{array}$ & $\begin{array}{l}\text { Tidak } \\
\text { wakil } \\
\text { Pemeri } \\
\text { ntah } \\
\text { Pusat } \\
\text { di } \\
\text { daerah }\end{array}$ & $\begin{array}{l}\text { Wakil } \\
\text { Gubernu } \\
\text { r secara } \\
\text { ex officio } \\
\text { menjadi } \\
\text { wakil } \\
\text { Gubernu } \\
\text { r sebagai } \\
\text { wakil } \\
\text { pemerint } \\
\text { ah pusat }\end{array}$ \\
\hline 3. & Sekretaris & Tidak & Sekretari \\
\hline
\end{tabular}




\begin{tabular}{|c|c|c|c|}
\hline $\begin{array}{l}\mathbf{N} \\
\mathbf{0}\end{array}$ & $\begin{array}{c}\text { Indikator } \\
\text { Perbandi } \\
\text { ngan }\end{array}$ & $\begin{array}{c}\text { UU } \\
\text { Nomor } \\
32 \\
\text { Tahun } \\
\mathbf{2 0 0 4}\end{array}$ & $\begin{array}{c}\text { UU } \\
\text { Nomor } \\
23 \\
\text { Tahun } \\
2014\end{array}$ \\
\hline & daerah & $\begin{array}{l}\text { wakil } \\
\text { pemeri } \\
\text { ntah } \\
\text { pusat } \\
\text { di } \\
\text { daerah }\end{array}$ & $\begin{array}{l}\text { s daerah } \\
\text { secara } \\
\text { ex- } \\
\text { officio } \\
\text { menjadi } \\
\text { sekretari } \\
\text { s } \\
\text { perangka } \\
\text { t } \\
\text { gubernur } \\
\text { sebagai } \\
\text { wakil } \\
\text { pemerint } \\
\text { ah pusat } \\
\text { di daerah }\end{array}$ \\
\hline 4 & $\begin{array}{l}\text { Unsur } \\
\text { yang } \\
\text { membantu } \\
\text { Guberbur } \\
\text { sebagai } \\
\text { wakil } \\
\text { pemerinta } \\
\text { h pusat di } \\
\text { daerah }\end{array}$ & $\begin{array}{l}\text { Tidak } \\
\text { ada } \\
\text { unsur } \\
\text { yang } \\
\text { dinyata } \\
\text { kan } \\
\text { dengan } \\
\text { jelas } \\
\text { dalam } \\
\text { UU } \\
\text { untuk } \\
\text { memba } \\
\text { ntu } \\
\text { Gubern } \\
\text { ur } \\
\text { sebagai } \\
\text { wakil } \\
\text { pemeri } \\
\text { ntah } \\
\text { pusat } \\
\text { di } \\
\text { daerah }\end{array}$ & $\begin{array}{l}\text { Gubernu } \\
\text { r dibantu } \\
\text { oleh } \\
\text { perangka } \\
\mathrm{t} \\
\text { Gubernu } \\
\text { r sebagai } \\
\text { wakil } \\
\text { pemerint } \\
\text { ah pusat }\end{array}$ \\
\hline 5. & $\begin{array}{l}\text { Bupati/Wa } \\
\text { likota }\end{array}$ & $\begin{array}{l}\text { Bukan } \\
\text { Wakil } \\
\text { Pemeri } \\
\text { ntah }\end{array}$ & $\begin{array}{l}\text { Bukan } \\
\text { Wakil } \\
\text { Pemerint } \\
\text { ah Pusat }\end{array}$ \\
\hline
\end{tabular}

\begin{tabular}{|c|c|c|c|}
\hline $\begin{array}{l}\mathbf{N} \\
\mathbf{0}\end{array}$ & $\begin{array}{c}\text { Indikator } \\
\text { Perbandi } \\
\text { ngan }\end{array}$ & $\begin{array}{c}\text { UU } \\
\text { Nomor } \\
\mathbf{3 2} \\
\text { Tahun } \\
\mathbf{2 0 0 4}\end{array}$ & $\begin{array}{c}\text { UU } \\
\text { Nomor } \\
23 \\
\text { Tahun } \\
\mathbf{2 0 1 4}\end{array}$ \\
\hline & & $\begin{array}{l}\text { Pusat } \\
\text { di } \\
\text { daerah }\end{array}$ & $\begin{array}{l}\text { di daerah } \\
\text { akan } \\
\text { tetapi } \\
\text { mendapa } \\
\text { tkan } \\
\text { pelimpah } \\
\text { an } \\
\text { kewenan } \\
\text { gan dari } \\
\text { Presiden } \\
\text { khusus } \\
\text { untuk } \\
\text { melaksa } \\
\text { nakan } \\
\text { urusan } \\
\text { pemerint } \\
\text { ahan } \\
\text { umum }\end{array}$ \\
\hline
\end{tabular}

\section{Sumber: Data Olahan Penulis,} 2017

Berdasarkan tabel di atas dapat diketahui bahwa pada UndangUndang Nomor 23 Tahun 2014 tentang pemerintahan Daerah sudah dinyatakan dengan jelas bahwa wakil gubernur secara ex-officio juga merupakan wakil Gubernur sebagai wakil pemerintah pusat, sehingga Wakil Gubernur dapat menggantikan fungsi Gubernur sebagai wakil pemerintah pusat apabila Gubernur berhalangan. Seperti dinyatakan pada Pasal 91 ayat (7) undang-undang Nomr 23 tahun 2014 yakni; "Tugas dan wewenanga Gubernur sebagai wakil pemerintah pusat di daerah dapat dilimpahkan kepada Wakil Guberbur".

Begitu juga dengan sekretaris daerah secara ex-officio juga menjadi 
sekretaris perangkat Gubernur sebagai wakil pemerintah pusat di daerah, karena di dalam Pasal 93 ayat (4) UU Nomor 23 Tahun 2014 secara jelas dinyatakan bahwa; Sekretaris Daerah Provinsi karena jabatannya ditetapkan sebagai Sekretaris Gubernur" .

Gubernur dibantu oleh perangkat Gubernur sebagai wakil pemerintah pusat di daerah, namun sampai saat ini kelembagaan perangkat Gubernur sebagai wakil pemerintah pusat belum terealisasi di daerah. Sehingga pada saat ini Gubernur sebagai wakil pemerintah pusat di daerah dibantu oleh perangkat daerah.

Hal ini tentunya

"kontroversial", apabila tugas Gubernur sebagai wakil Pemerintah pusat di laksanakan oleh perangkat daerah, karena dalam UndangUndang Nomr 23 Tahun 2014 ini secara jelas dinyatakan bahwa perangkat daerah berfungsimembantu Gubernur sebagai Kepala daerah bukan berfungsi membantu Gubernur sebagai wakil pemeritah pusat di daerah.

\section{Unsur dan Tugas Perangkat Gubernur Sebagai Wakil Pemerintah Pusat Di Daerah}

Dalam melaksanakan fungsi Gubernur sebagai wakil pemerintah pusat di daerah, maka secara jelas dalam Undang-Undang Nomor 23 Tahun 2014 tentang Pemerintahan daerah dinyatakan bahwa Gubernur dibantu oleh Perangkat Gubernur sebagai wakil pemerintah pusat di daerah. Oleh karena gubernur melaksanakan fungsi sebagai wakil pemerintah pusat di daerah maka unsur perangkat gubernur sebagai wakil pemerintah pusat di daerah tentu berasal dari pegawai negeri sipil (PNS) pusat.

Perangkat Gubernur sebagai wakil pemerintah pusat di daerah dikepalai oleh seorang sekretaris daerah secara ex-officio, hal ini sudah dinyatakan dengan jelas dalam Undang-undang Nomir 23 Tahun 2014 tentang Pemerintahan Daerah, bahwa sekretaris daerah secara exofficio oleh sekretaris daerah.

Namun secara realita keberadaan dari perangkat gubernur sebagai wakil pemerintah pusatbelum terbentuk di daerah, hal ini juga disebabkan oleh:

1. Belum adanya peraturan pemerintah tentang perangkat Gubernur sebagai wakil pemerintah pusat di daerah, sehigga sampai saat ini perangkat Guberbur sebagai wakil pemerintah pusat belum terbentuk.

2. Kewenangan membentuk perangkat Gubernur sebagai wakil pemerintah pusat di daerah merupakan kewenangan dari pemerintah pusat, sehingga pembentukan perangkat Gubernur sebagai wakil pemerintah pusat di seluruh provinsi di Indonesia menjadi lambat dan tersendat, karena harus menunggu inisiatif dari penerintah pusat.

3. Pemerintah pusat masih kesulitan untuk memenuhi kebutuhan pegawai pemerintah pusat untuk ditempatkan sebagai pegawai perangkat gubernur sebagai wakil pemerintah 
pusat di daerah pada seluruh provinsi yang ada di negara kesatuan Republik Indonesia.

\section{Anggaran dan Pelaporan Fungsi Gubernur Sebagai Wakil Pemerintah Pusat Di Daerah.}

Dalam melaksanakan fungsi Gubernur sebagai wakil pemerintah pusat di daerah berdasarkan UndangUndang Nomor 23 Tahun 2014 tentang Pemerintahan daerah seluruhnya menggunakan anggaran yang berasal dari Aggaran Pendapatan dan Belanja Negara (APBN), karena pada hakekatnya urusan yang dieselenggarakan oleh Guberbur sebagai wakil pemerintah pusat di daerah merupakan tugas dari pemerintah pusat yang dilimphkan keweangannya kepada Gubernur. Seperti dinyatakan pada Pasal 91 ayat (5) Undang-Undang Nomor 23 Tahun 2014, yakni; Pendanaan terhadap pelaksanaan tugas dan wewenang Gubernur sebagai wakil pemerintah pusat".

Begitu juga dengan gaji dari perangkat Gubernur sebagai wakil pemerintah pusat di daerah berasal dari Anggaran Pendapatan dan Belanja Negara (APBN), karena pada hakekatnya pegawai dari perangkat Gubernur sebagai wakil penerintah pusat di daerah adalah pegawai dari pemerintah pusat, sehingga menjadi tanggugjawabpenerintah pusat untuk menggaji pegawai perangkat Guberbur sebagai wakil pemerintah pusat di daerah.

Seluruh urusan yang dilaksanakan oleh Gubernur sebagai wakil pemerintah pusat dilaporkan kepada pemerintah pusat, karena urusan pemerintah tersebut merupakan urusan yang menjadi kewenangan pemerintah pusat, Gubernur sebagai wakil pemerintah pusat di daerah hanya mendapatkan "pelimpahan kewenangan" dari pemerintah pusat, oleh karena itu pada prinsinya dari mana urusan tersebut dilimpahkan kewenangannya (diperoleh) maka pelaporannya kembali kepada yang melimpahkan kewenangan.

Oleh karena itu, urusan pemerintahan yang dilaksanakan oleh Guberbur sebagai wakil pemerintah pusat tidak dilaporkan dalam Laporan Keterangan Pertanggugjawaban (LKPJ) kepala daerah kepada Dewan Perwakilan Rakyat Daerah (DPRD), karena urusan yang dilimpahkan oleh pemerintah pusat tersebut dilimpahkan kepada Guberbur sebagai wakil pemerintah pusat di daerah dan bukan dilimpahkan kewenangannya kepada Guberbur sebagai Kepala Daerah, sehigga tidak dilaporkan dalam LKPJ kepala Daerah.

\section{Kesimpulan}

a. Untuk menyelenggarakan urusan pemerintahan pusat yang menjadi kewenangan pemerintah pusat dilimpahkan kepada Gubernur sebagai wakil pemerintah pusat.

b. Kapasitas Gubernur sebagai wakil pemerintah pusat menggunakan asas dekonsentrasi.

c. Guberbur sebagai wakil pemerintah pusat di daerah memiliki tugas dalam bentuk koordinasi, pengawasan dan pembinaan. 
d. Pelimpahan

kewenangan pemerintah pusat kepada wakil pemerintah pusat di daerah hanya diserahkan kepada Gubernur sebagai wakil pemerintah pusat di daerah, sedangkan Bupati/Walikota tidak ada dinyatakan sebagai wakil pemerintah Pusat di daerah pada Undang-undang Nomor 23 Tahun 2014 tentang Pemerintahan Daerah.

\section{Saran}

a. Disarankan kepada pemerintah untuk secepatnya membuat Peraturan Pemerintah tentang Gubernur Sebagai wakilpemerintah pusat di daerah.

b. Disarankan kepada pemerintah untuk sesegera mungkin membentuk Perangkat Gubernur sebagai wakil pemerintah pusat di daerah.

\section{Daftar Kepustakaan}

di Keamatan, M. P. N. S., \& Hulu, S. Evaluasi Pelaksanaan Peraturan Pemerintah Nomor 45 Tahun 2007 Tentang Persyaratan dan Tata Cara Pengangkatan Sekretaris Desa.

Ispik, A., Yogia, M. A., Wedayanti, M. D., \& Zainal, Z. (2021). The Influence of Discipline on Performance of Employees Office of the Ministry of Religion. Pekanbaru City.

Subhayano, T., Yogia, M. A., Wedayanti, A. A. P. M. D., \& Zainal, M. L. H. (2021). Good Governance in Maintaining Peace and Order at Pangkalan Kerinci District. Pelalawan Regency.

Ispik, A., Yogia, M. A., Purwati, A. A., Wedayanti, M. D., \& Zainal, M. L. H. (2021). Analysis of Benefits, Discipline and Leadership Style in improving Employee Performance of the Ministry of Religion in Pekanbaru, Indonesia.

Nasri, H., Nurman, N., Azwirman, A., Zainal, Z., \& Riauan, I. (2022). Implementation of collaboration planning and budget performance information for special allocation fund in budget planning in the regional development planning agency of Rokan Hilir regency. International Journal of Health Sciences (IJHS) Ecuador, 6(S4), 639-651.

Munir, A., Wahyudi, S., \& Zainal, Z. (2020). Tinjauan Kriminologi Terhadap Sensual Marketing Sebagai Strategi Pemasaran Produk Yang Diperankan Oleh Sales Promotion Girl Di Kota Pekanbaru. Wedana: Jurnal Kajian Pemerintahan, Politik dan Birokrasi, 6(2), 21-35.

Subhayano, T., Yogia, M. A., Wedayanti, M. D., \& Zainal, Z. (2021). The Role of the Camat in Coordinating the Administration of Peace and Order in Pangkalan Kerinci District Pelalawan Regency.

Suwaryo, H. U., \& Redjo, H. S. I. (2018). Transformasi Hubungan Pemerintah Pusat Dan Pemerintah Daerah Dalam Pemberian Izin Hutan Tanaman Industri Bagi Swasta Di Provinsi Riau Tahun 2010-2015.

Wicaksono, A. (2022, April). Peatlands Restoration Policies in Indonesia: Success or Failure?. In IOP Conference Series: Earth and Environmental Science (Vol. 995, No. 1, p. 012068). IOP Publishing. Yogia, A. S. M. A., Rahman, Z. M. D. W. K., \& Purwati, A. A. (2021). Leadership of Tourism and Culture Department in Development of Cultural Reserves at District Kuantan Singingi. 
Zainal, Z., Rambey, R. R., \& Rahman, K. (2021). Governance of Household Waste Management in Pekanbaru City. MIMBAR: Jurnal Sosial dan Pembangunan, 37(2).

Halim, N. A., Rosidi, I., Haris, A., Yesicha, C., \& Riauan, M. A. I. Media dan Politik.

Riauan, M. A. I., Aziz, A., \& Nurman, N. (2020). Analisis Framing" Aksi Bela Islam" sebagai Dakwah Islam di Riau Pos (A Framing Analysis of" Islam Defense Action" as Islamic Dakwah on Riau Pos Newspaper). Jurnal Dakwah Risalah, 31(1), 35-47.

Riauan, M. A. I., Qurniawati, E. F., Aslinda, C., \& Aziz, A. (2020). Konstruksi Realitas Pada Pesan Politik Calon Walikota Pekanbaru di Riau Pos. ETTISAL: Journal of Communication, 5(1).

Riauan, M. A. I., Kholil, S., \& Sikumbang, A. T. (2019). Islamic Symbols on Political Messages in Newspapers in Riau (Study in Regional Head Election 2017). Budapest International Research and Critics InstituteJournal (BIRCI-Journal), 2(1), 254-262.

Riauan, M. A., Sari, G. G., Aslinda, C., \& Qurniawati, E. F. (2018). Konstruksi Makna Ketergantungan dalam Perilaku Merokok. Relasi Negara Industri Dan Masyarakat Dalam Perspektif Komunikasi, 171.

Riauan, M. A. I., \& Shasrini, T. (2017). Dampak Komunikasi Terapeutik terhadap Citra Pelayanan Kesehatan (Studi Kasus di Rumah Sakit Umum Daerah Arifin Achmad Pekanbaru). Jurnal The
Messenger, 9(1), 31-43.

Riauan, M. A. I. (2016). Figur Politik Calon Walikota Pekanbaru Septina Primawati Rusli dan Erizal Muluk Pada Pemilukada Kota Pekanbaru 2011. Medium, 4(2).

Riauan, M. A. I. (2013). Penggunaan Teknologi Komunikasi dalam Penerapan Good Governance. Jurnal Kajian Pemerintahan, 2(2), 102-107.

Riauan, M. A. I. (2012). Studi Komparatif Aktivitas Humas Antara Pemerintah Provinsi Riau dengan PT. Chevron Pacific Iindonesia. Medium, 1(1).

Sari, G. G., Wirman, W., \& Riauan, M. A. (2018). Pergeseran Makna Tradisi Bakar Tongkang Bagi Generasi Muda Tionghua di Kabupaten Rokan Hilir Provinsi Riau. 